\title{
Microstructure and Mechanical Properties of C/C Composites with Different Configuration of Unidirectional Macropores
}

Jiangang Jia ( $\square$ jiajg@lut.edu.cn )

State Key Laboratory of Advanced Processing and Recycling of Non-ferrous Metals, Lanzhou University of Technology

Jiakang Ju

State Key Laboratory of Advanced Processing and Recycling of Non-ferrous Metals, Lanzhou, China Shunwei Liu

State Key Laboratory of Advanced Processing and Recycling of Non-ferrous Metals, Lanzhou, China Genshun Ji

State Key Laboratory of Advanced Processing and Recycling of Non-ferrous Metals, Lanzhou, China

\section{Research Article}

Keywords: C/C composites, space-holder, PyC matrix

Posted Date: October 12th, 2020

DOl: https://doi.org/10.21203/rs.3.rs-88301/v1

License: (c) (i) This work is licensed under a Creative Commons Attribution 4.0 International License. Read Full License 


\section{Abstract}

The unidirectional porous $\mathrm{C} / \mathrm{C}$ composites with different channel-diameter and channels-row spacing were prepared by a space-holder route. The effects of different channel-diameter and channels-row spacing on the mechanical properties and microstructures of the porous $\mathrm{C} / \mathrm{C}$ composites were studied. Results show that increasing the channel-diameter or reducing the channels-row spacing helps to obtain finer PyC grains but significantly reduce the matrix density of the composites, and, in turn, the compressive strength of the composites. Porous $\mathrm{C} / \mathrm{C}$ composites with lower porosity or higher density (e.g., $S_{5,2}$ ) present relatively high strength, whereas $C / C$ porous composites with lower density or higher porosity show a pseudo-plastic fracture mode and relatively lower strength. The compression strength in the load parallel to channel direction is higher than that in the load perpendicular to channel direction of the same composite.

\section{Introduction}

$\mathrm{C} / \mathrm{C}$ composites have a wide range of applications in many industrial products, especially in aeronautics and astronautics, due to the advantages of light weight, high thermal shock resistance, low coefficient of thermal expansion (CTE), null coefficient of moisture expansion (CME), high impact resistance, high wear resistance and high stiffness, etc. [1-4]. Among various advanced $\mathrm{C} / \mathrm{C}$ composites, $\mathrm{C} / \mathrm{C}$ sandwiches composed of $\mathrm{C} / \mathrm{C}$ panels and $\mathrm{C} / \mathrm{C}$ honeycombs are selected to make ultra-stable structures to guarantee a near to zero CTE and accurate relative positioning of components for both in-orbit and ground-and-orbit operations [5, 6]. Inevitably, weak bonding joints exist between the panels and honeycombs, leading to deteriorated mechanical and high temperature performances of the $\mathrm{C} / \mathrm{C}$ sandwiches [7]. Therefore, it is meaningful to seek other optional strategies for heavily loaded structures with light-weight for future space applications.

To use the advantage of $\mathrm{C} / \mathrm{C}$ composites and reduce the density without significantly reducing the compressive strength, a space-holder route has been designed to fabricate unidirectional porous $\mathrm{C} / \mathrm{C}$ composites out of commercial carbon felt preforms [8]. Five principal steps, i.e., wax soaking and curing of carbon felt preforms, prefabrication of channels, filling space-holder and removing wax, depositing carbon matrix, and leaching out space-holder were involved in the special designed space-holder route. The results show that the channel pore diameter intensively affects the microstructure and compressive properties of the unidirectional porous $\mathrm{C} / \mathrm{C}$ composites.

It is noted that the commercial carbon felt preforms were made from short polyacrylonitrile (PAN) fibers, which underwent peroxidation, oxidation, and carbonization process without stretching. Since stretching process is an essential factor to improve tensile strength of PAN based carbon fibers through molecular orientation $[9,10]$, the mechanical properties of carbon fibers in commercial felt preforms should be considerably inferior to that of continuous carbon fibers. In general, different kind of carbon fiber components would result in different properties of the final composites. However, whether porous $\mathrm{C} / \mathrm{C}$ composites made of stronger carbon fiber preforms have improved mechanical properties remains 
obscure and open to question. In addition, effects of different configuration of unidirectional pores on mechanical properties of C/C composites also need to be clarified. In the present study, needled 2Dnonwoven carbon fiber layers (composed of T300 carbon fibers which is much stronger than commercial carbon felt) are intentionally selected as the preform to fabricate porous $\mathrm{C} / \mathrm{C}$ composites based on the reported space-holder method [8], and the microstructure of the $\mathrm{C} / \mathrm{C}$ matrix and compressive strength of the unidirectional porous $\mathrm{C} / \mathrm{C}$ composites loading from two different directions are evaluated.

\section{Experimental}

\subsection{Materials and methods}

Nonwoven 2D carbon fiber layers were needled together to a density of about $0.34 \mathrm{~g} / \mathrm{cm}^{3}$ as the preform and was cut into a ring-shape with the dimensions of approximately $85 \mathrm{~mm}$ o.d. $\times 45 \mathrm{~mm}$ i.d. $\times 10 \mathrm{~mm}$ thickness. Paraffin (wax) with a melting point between $47-64^{\circ} \mathrm{C}$ was used to facilitate the prefabrication of unidirectional holes in the preform. As schematically shown in Figure 1, the ring-shaped preform was impregnated by molten wax to maintain shape. Then unidirectional channels with diameters of $2 \mathrm{~mm}, 2.5$ $\mathrm{mm}, 3 \mathrm{~mm}$, and channels and columns-row spacing of $5 \mathrm{~mm}$ were punctured in the preform with the aid of a pair of unidirectional porous stencils. For the preforms with a diameter of $2 \mathrm{~mm}$, different preforms with row (and column) spacing of $5 \mathrm{~mm}, 4 \mathrm{~mm}$, and $3 \mathrm{~mm}$ were arranged. The corresponding porous $\mathrm{C} / \mathrm{C}$ composites prepared from the above pretreated preforms were assigned as $S_{5,2}, S_{5,2.5}, S_{5,3}, S_{4,2}$, and $S_{3}$, 2. The first subscript refers to the row (or column) spacing and the second one represents the channel diameter.

Figure1 shows Flow diagram of preparation of unidirectional porous $\mathrm{C} / \mathrm{C}$ composites. Before deposition, a space-holder suspension composed of $\mathrm{Na}_{2} \mathrm{O} \cdot \mathrm{nSiO}_{2} \cdot \mathrm{mH}_{2} \mathrm{O}$ (47 wt \%), $\mathrm{Na}_{2} \mathrm{SiF}_{6}\left(6 \mathrm{wt} \%\right.$ ), and $\mathrm{SiO}_{2}$ (47 wt $\%)$ was filled into the prefabricated channels. After naturally cured, the preform was immersed in boiling water to remove the impregnated wax. Densification was carried out via a thermal gradient-chemical vapor infiltration (TG-CVI) process at $1080^{\circ} \mathrm{C}$ and $5 \mathrm{kPa}$. Propane $\left(\mathrm{C}_{3} \mathrm{H}_{8}\right)$ and $\mathrm{N}_{2}$ were used as the precursor and dilution gas with flow rates of 150 and $450 \mathrm{ml} / \mathrm{min}$, respectively. The deposition duration was $60 \mathrm{~h}$.

After manually grinding off the thin pyrocarbon $(\mathrm{PyC})$ crust covered on the composites and leaching out the space-holders, unidirectional porous $\mathrm{C} / \mathrm{C}$ composites were obtained.

\subsection{Characterization}

Density of C/C matrix part of the unidirectional porous composites was measured by Archimedes' drainage method. Compressive strengths of the porous $\mathrm{C} / \mathrm{C}$ composites along the channel direction $\left(\mathrm{P}_{/ /}\right)$ and perpendicular to the channel axis $(\mathrm{P} \perp)$ (refer to Figure 2) were tested using MTS E44.304 electronic universal testing machine with a loading speed of $0.5 \mathrm{~mm} / \mathrm{min}$. The samples size was 
$10 \mathrm{~mm} \times 10 \mathrm{~mm} \times 8 \mathrm{~mm}$. At least three specimens were tested under each test condition. The compressive strength $P$ is calculated using formula (1):

$$
P=\frac{F}{S}
$$

where $\mathrm{F}$ is the fracture force and $\mathrm{S}$ is the total cross-sectional area of the specimen.

The macrographs of the pretreated preforms, pore channels, columnar space-holders and the final porous $\mathrm{C} / \mathrm{C}$ composites were observed by SMZ18 volume microscope. The phase composition of the composite was investigated using a Rigaku D/Max-2400 X-ray diffractometer. The microstructure of the $\mathrm{C} / \mathrm{C}$ matrix part was observed using a Zeiss Axio Imager A2M type of polarized light microscope (PLM). The fracture morphology of the compressed specimen was observed using a FEG-450 scanning electron microscope (SEM).

\section{Results And Discussion}

Figure 3 (a) presents the macro-morphologies of the wax-impregnated carbon fiber preforms with needlepunched unidirectional channels. It shows that the preform is properly cured by the wax, and the prefabricated round channels are fairly maintained neatly arranged. Figure 3 (b) shows the cross section of the preform with space-holders filled in the channels. At this stage, the space-holders are composed of $\mathrm{SiO}_{2}$ (major ingredients) and $\mathrm{NaF}$ (minor ingredients) according reaction (2) and the contents of the starting materials.

$$
2 \mathrm{Na}_{2} \mathrm{O} \cdot n \mathrm{SiO}_{2} \cdot \mathrm{mH}_{2} \mathrm{O}+\mathrm{Na}_{2} \mathrm{SiF}_{6} \rightarrow(2 n+1) \mathrm{SiO}_{2} \cdot 2 \mathrm{mH}_{2} \mathrm{O}+6 \mathrm{NaF}
$$

The space-holders exhibits a solid and dense morphology, and are well confined in the channels. Obviously, wax-impregnated carbon fibers prevent the space-holder particles trapped into the preform body beyond the channel. Based on this preform treating method, many other ingredients (E.g. phenolic resin-Si powder slurry for $\mathrm{SiC}$ formation) can be designed and combined into the final $\mathrm{C} / \mathrm{C}$ composite with a columnar configuration. But this has been out of the scope of the present paper. Figure 3 (c) demonstrate the morphologies of preform after wax-removing. In this stage the $\mathrm{NaF}$ in the space-holders should have been largely dissolved into the boiling water, and thus the $\mathrm{SiO}_{2}$ content in the cylindrical space-holder increases. It clearly shows that the space-holders are still tightly embedded in the preform, which has become ventilated and clean and ready for densification.

Figure 4 (a) shows the photograph of the deposited state of the composites. After densification the outermost layer is covered with a bright white PyC crust. Figure 4 (b) reveals the morphology of the 
composite after removing the thin $\mathrm{PyC}$ crust. Arrayed columnar $\mathrm{SiO}_{2}$ firmly embedded in the $\mathrm{C} / \mathrm{C}$ matrix; this composite itself can be regarded as a new type of $\mathrm{C} / \mathrm{C}-\mathrm{SiO}_{2}$ composite. After leaching out $\mathrm{SiO}_{2}$ (the space-holder), the unidirectional porous $\mathrm{C} / \mathrm{C}$ composite $\mathrm{S}_{5,2}$ is displayed in Figure 4 (c). The $\mathrm{C} / \mathrm{C}$ matrix look dense and the cross-sectional inner wall of the pores appear smooth, indicating that the channels are properly preserved by the space-holders.

Figure 5 depicts the PLM microstructures of the porous $\mathrm{C} / \mathrm{C}$ composites with different channel diameters and row-spacings. $\mathrm{PyC}$ is normally classified into three basic types based on the morphology of $\mathrm{C} / \mathrm{C}$ composites under polarized light microscope (PLM): Rough laminar (RL), smooth laminar (SL) and optical isotropic (ISO) structure [11, 12]; or according to the extinction angle $\left(A_{e}\right)$ under polarized light, the textures of PyC are quantitatively classified into isotropic PyC (ISO, $\left.A e=0^{\circ}\right)$, low-textured PyC $\left(\mathrm{LT}, 0^{\circ}<\mathrm{A}_{e}\right.$ $\left.\leq 12^{\circ}\right)$, medium-textured $\operatorname{PyC}\left(M T, 12^{\circ}<A_{e} \leq 18^{\circ}\right)$ and high-textured $\operatorname{PyC}\left(H T, A_{e}>18^{\circ}\right)[13,14]$.

Fig. 5 (a) shows the PLM photomicrograph of the composite with row-spacing of $5 \mathrm{~mm}$ and channeldiameters of $2 \mathrm{~mm}\left(\mathrm{~S}_{5,2}\right)$. Growth cones initialized from the surface of carbon fibers and disrupted Maltese extinction crosses with the $A_{e}$ of $18.9^{\circ} \pm 0.6^{\circ}$ are observed, characterizing a high texture or RL PyC matrix. The textures of $S_{5,2.5}$ [Fig. 5 (b)] and $S_{5,3}$ [Fig. 5 (c)] are similar as that of $S_{5,2}$, indicating that different channel-diameters with the row-spacing of $5 \mathrm{~mm}$ have little effects on the microstructures of the porous $\mathrm{C} / \mathrm{C}$ composites. The grain size of the pyrolytic carbon of $\mathrm{S}_{4,2}$ and $\mathrm{S}_{3,2}$ is significantly refined compared with that of $S_{5,2}$, as evidenced in Figure 5 (d) and (e), respectively. This apparently due to preform densities of $S_{4,2}$ and $S_{3,2}$ are higher than that of $S_{5,2}, S_{5,2.5}$, and $S_{5,3}$, because the channels-row spacing in $S_{4,2}$ and $S_{3,2}$ is lower than that in $S_{5,2}, S_{5,2.5}$, and $S_{5,3}$. Apart from fine PyC grains with RL or high-textures, larger PyC grains (marked with arrow) with annular cracks and distinct extinction crosses that characterize SL or low- to middle-textured PyC also present in Figure 5 (d). PyC with two or more matrix structures is called a banded structure [12]. Many factors, such as precursor gas used, temperature, partial pressure, area/volume (A/V) value, etc., affect the PyC texture [12, 15], among which, the volume related concentration of active sites (A/V ratio) directly influence the kinetics of deposition as well as the texture of PyC matrix [16]. It is easy to see that the larger PyC grains mainly appear in areas where carbon fiber is relatively sparse.

Figure 6 shows the compressive strengths of the porous $\mathrm{C} / \mathrm{C}$ composites for $\mathrm{P}_{/ /}$and $\mathrm{P}_{\perp}$. For porous $\mathrm{C} / \mathrm{C}$ composites with fixed channel-row spacing, both $\mathrm{P}_{/ /}$and $\mathrm{P} \perp$ decrease as the channel-diameter increases [Fig. 6 (a)]; for the porous samples with a fixed channel-diameter of $2 \mathrm{~mm}$, the $\mathrm{P}_{/ /}$and $\mathrm{P} \perp$ decrease with the decreasing of channels-row spacing [Fig. 6 (b)]. This reflects that the strength of porous materials decreases with increasing of the overall porosity [17-19]. The $P_{/ /}$for $S_{5,2}, S_{5,2.5}$ and $S_{5,3}$ are $104 \pm 6.6 \mathrm{MPa}$, 75.8 $\pm 4.3 \mathrm{MPa}$ and $43.5 \pm 3.8 \mathrm{MPa}$, respectively; $\mathrm{P} \perp$ for the corresponding samples are $72.1 \pm 3.2 \mathrm{MPa}$, $57 \pm 3.5 \mathrm{MPa}$ and $35.6 \pm 2.8 \mathrm{MPa}$, respectively. Strength anisotropy arise mainly due to the bearing area percentage of the cross-section for $P_{/ /}$is larger than that of $P \perp[8]$. The $P_{/ /}$for $S_{5,2}, S_{4,2}$ and $S_{3,2}$ are $104 \pm 6.6 \mathrm{MPa}, 45.1 \pm 2.7 \mathrm{MPa}$ and $39.5 \pm 2.3 \mathrm{MPa}$, respectively; $\mathrm{P} \perp$ for the corresponding samples are 
72.1 $\pm 3.2 \mathrm{MPa}, 35.3 \pm 2 \mathrm{MPa}$ and $33.7 \pm 2.1 \mathrm{MPa}$, respectively. The decrease in strength is consistent with the decrease in density or increase in porosity. The average densities of $C / C$ matrix part of $S_{5,2}, S_{5,2.5}, S_{5}$, ${ }_{3}, S_{4,2}$ and $S_{3,2}$ are $1.71 \pm 0.04,1.69 \pm 0.03,1.66 \pm 0.04,1.58 \pm 0.05$, and $1.54 \pm 0.05 \mathrm{~g} / \mathrm{cm}^{3}$, respectively. Figure 6 (a) and (b) clearly shows that densities of matrix of the unidirectional porous $\mathrm{C} / \mathrm{C}$ composites decrease with the increasing of channel-diameter or decreasing of channels-row spacing. This is because the decrease in the channels-row spacing or increasing of channel-diameter of the same volume composites will relatively increase the number or volume of channels, causing the increase in porosity and reducing the density of the composite matrix.

Increasing of channel density (i.e., decreasing channel-row spacing) or increasing of channel-diameter result in an increasing density of carbon fiber preform outside the channels part, and, in turn, lead to a more lengthy and complicated gas flow path through the preform [20]. Thus, under identical CVI densification manner, less PyC is deposited in the higher density preforms within the same time.

Figure 7 (a) and (b) demonstrates representative load-displacement curves of the porous $\mathrm{C} / \mathrm{C}$ composites for $\mathrm{P} / /$ and $\mathrm{P} \perp$ testing, respectively. For the $\mathrm{P} / /$ curves, $\mathrm{S}_{5,2}, \mathrm{~S}_{5,2.5}$, and $\mathrm{S}_{4,2}$ display a catastrophic rather than non-catastrophic failure mode with unimportant pseudo-plastic behavior, except that the failure load for $S_{4,2}$ is much lower than that for $S_{5,2}$ and $S_{5,2.5} . S_{5,3}$, and $S_{3,2}$, however, show pronounced pseudoplastic fracture behavior for both $\mathrm{P} / /$ and $\mathrm{P} \perp$ tests. It is meaning to compare the load-displacement curves of $S_{5,3}$, and $S_{4,2}$. The failure loads for both are comparable, but $S_{5,3}$ shows a linear elasticity at low stress followed by a long yield plateau, behaving more like a typical metal porous material [18, 21]; whereas $S_{4,2}$ exhibits a more brittle behavior characterized with a quick load-drop after peak value in the load-displacement curve. The slope of the linear modulus line of $S_{3,2}$ is apparent lower than other porous $\mathrm{C} / \mathrm{C}$ composite samples, which should be because $\mathrm{S}_{3,2}$ has the largest porosity.

Figure 8 shows SEM fracture morphologies of the porous $\mathrm{C} / \mathrm{C}$ composites. The fracture features of $\mathrm{S}_{5,2}$ [Fig. 8 (a)] and $S_{5,2.5}$ [Fig. 8 (b)] are alike and characterized by relatively flat fracture surfaces with very short pullout fiber length, indicating that a strong interface bonding between the fibers and the matrix, and also reasoning that $S_{5,2}$ and $S_{5,2.5}$ possess very similar compressing behaviors of relatively high strength and brittleness. Cracks occur at the matrix defect when brittle fracture begins and propagates, as shown by the red arrow in Figure 8 (a), and eventually lead to the composite fail with the increase of load. The fracture features of $S_{5,3}$ [Fig. 8 (c)] also demonstrate a brittle fracture with short pulled-out fibers, suggesting that its pseudo-plastic behavior shown in Figure 7 (a) and (b) originates from the unidirectional pores. $S_{4,2}$ [Fig. 8 (d)] displays brittle fracture surface with delaminated fiber and PyC matrix. Whereas $S_{3,2}$ [Fig. 8 (e)] exhibits a compression fracture characterized with very long pulled-out fibers, indicating that a weak bonding strength between the fibers and the matrix, which results from the low density of $S_{3,2}$. Under the loading stress, the interface between fiber and matrix debonded easily. Combined with a high density of unidirectional pores, $S_{3,2}$ presents the lowest compression strength. 


\section{Conclusion}

In this study, the unidirectional macropores $\mathrm{C} / \mathrm{C}$ composites with different channel-diameter and channels-row spacing were prepared by the space-holder route. Results show that wax soaking treatment is a good way to maintain shape of the preforms and beneficial for prefabricating the unidirectional channels. The prefabricated channels can be properly reserved by the $\mathrm{SiO}_{2}$ space-holders. Increasing the channel diameter or reducing channels-row spacing helps to obtain finer PyC grains. The density of the unidirectional porous $\mathrm{C} / \mathrm{C}$ composites matrix also decreases with increasing of the channel-diameter or decreasing of the channels-row spacing. The compressive strength of the composites decreases with decreasing in density or increasing in porosity. Moreover, the compression strength in the load parallel to channel direction is higher than that in the load perpendicular to channel direction of the same composite. Additionally, unidirectional porous $\mathrm{C} / \mathrm{C}$ composites with low porosity or high density (e.g. $\left.S_{5,2}\right)$ present relatively high strength; decreasing in density or increasing in porosity leads to a pseudo-plastic fracture mode, analogous to the typical foam materials.

\section{Declarations}

\section{Acknowledgements}

This work was fifinancially supported by the National Natural Science Foundation of China (no.51461029) and Gansu Province science and technology major projects (no. 1602GKDD012).

\section{References}

1. M. F. Ashby, R. F. Mehl Medalist. The mechanical properties of cellular solids. Metall Mater Trans A. 14 (1983) 1755-1769.

2. L. Feng, K. Li, Z. Zhao, H. Li, L. Zhang, J. Lu, Q. Song, Three-dimensional carbon/carbon composites with vertically aligned carbon nanotubes: Providing direct and indirect reinforcements to the pyrocarbon matrix, Materials \& Design 92 (2016) 120-128.

3. Jin, X, Hou, C, Li, C, Wang, X, \& Fan, X. Strain rate effect on mechanical properties of 3d needlepunched C/C composites at different temperatures. Composites Part B: Engineering, 160(MAR.1), (2019)140-146.

4. Z.W. Yang, C.L. Wang, Y. Han, Y.T. Zhao, Y. Wang, D.P. Wang, Design of reinforced interfacial structure in brazed joints of $\mathrm{C} / \mathrm{C}$ composites and $\mathrm{Nb}$ by pre-oxidation surface treatment combined with in situ growth of CNTs, Carbon 143 (2019) 494-506.

5. M. Lutz, Y. Vitupier, L. Pambaguian, Evaluation of ultrastable carbon/carbon sandwich structures joined with ceramic cement, 61st International Astronautical Congress, Prague, CZ. (2010) pp. 1-4.

6. M. Salvo, V. Casalegno, Y. Vitupier, L. Cornillon, L. Pambaguian, M. Ferraris, Study of joining of carbon/carbon composites for ultra stable structures, J. Eur. Ceram.Soc. 30 (2010) 1751-1759 
7. F. Panin, M. Lutz-Nivet, H. Lemaire, Development of carbon-carbon sandwich panels, Proceedings of the 9th International Symposium on Materials in a Space Environment Noordwijk, The Netherlands, (2003) pp. 81-86.

8. J. Jia, S. Liu, T. Xia, B. Zhang, S. Zhang, G. Ji, Novel unidirectional porous carbon/carbon composites prepared by a special designed space holder method, Ceramics International 46 (10) (2020) 1519715205.

9. J.C. Chen, I.R. Harrison, Modification of polyacrylonitrile (PAN) carbon fiber precursor via postspinning plasticization and stretching in dimethyl, Carbon, 40 (2002) 25-45.

10. G. Wu, C. Lu, L. Ling, A. Hao, F. He, Influence of tension on the oxidative stabilization process of polyacrylonitrile fibers, Journal of Applied Polymer Science, 96 (2005) 1029-1034.

11. Pierson HO, Lieberman ML, The chemical vapor deposition of carbon on carbon fibers, Carbon, 13 (1975) 159-166.

12. Lieberman ML, Pierson HO. Effect of gas phase conditions on resultant matrixpyrocarbons in carbon carbon composites. Carbon 12 (1974) 233-241.

13. A. Oberlin. Pyrocarbons, Carbon. 40 (2002) 7-24.

14. B. Reznik, K.J. Huttinger, On the terminology for pyrolytic carbon, Carbon. 40 (2002) 617-636.

15. M. Guellali, R. Oberacker, M.J. Hoffmann, Influence of the matrix microstructure on the mechanical properties of CVI-infiltrated carbon fiber felts, Carbon 43 (9) (2005) 1954-1960.

16. 16. Hu ZJ, Zhang WG, Hüttinger KJ, Reznik B, Gerthsen D. Influence of pressure, temperature and surface area/volume ratio on the texture of pyrolytic carbon deposited from methane. Carbon 41 (4) (2003) 749-758.

17. A. Jinnapat, A.R. Kennedy. The manufacture of spherical salt beads and their use as dissolvable templates for the production of cellular solids via a powder metallurgy route, Journal of Alloys and Compounds 499 (1) (2010) 43-47.

18. Ashby MF, Evans AG, Fleck NA, Gibson LJ, Hutchinson JW, Wadley HNG, Metal foams: a design guide, Materials and Design 23 (2002) 2119-2120.

19. A.M. Parvanian, M. Panjepour, Mechanical behavior improvement of open-pore copper foams synthesized through space holder technique, Materials \& Design 49 (2013) 834-841.

20. Lu XF, Zhang J, Qian K, Densification rate and mechanical properties of carbon/carbon composites with layer-designed preform, Ceram Int. 45 (2019) 4167-4175.

21. M. F. Ashby, R. F. Mehl Medalist. The mechanical properties of cellular solids. Metall Mater Trans A. 14A (1983) 1755-1769.

\section{Figures}




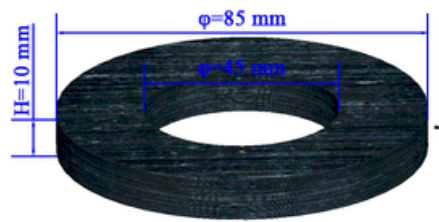

2D needled carbon fiber preform

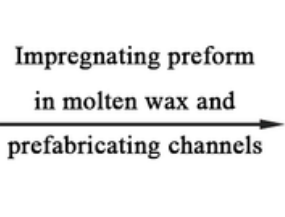

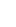

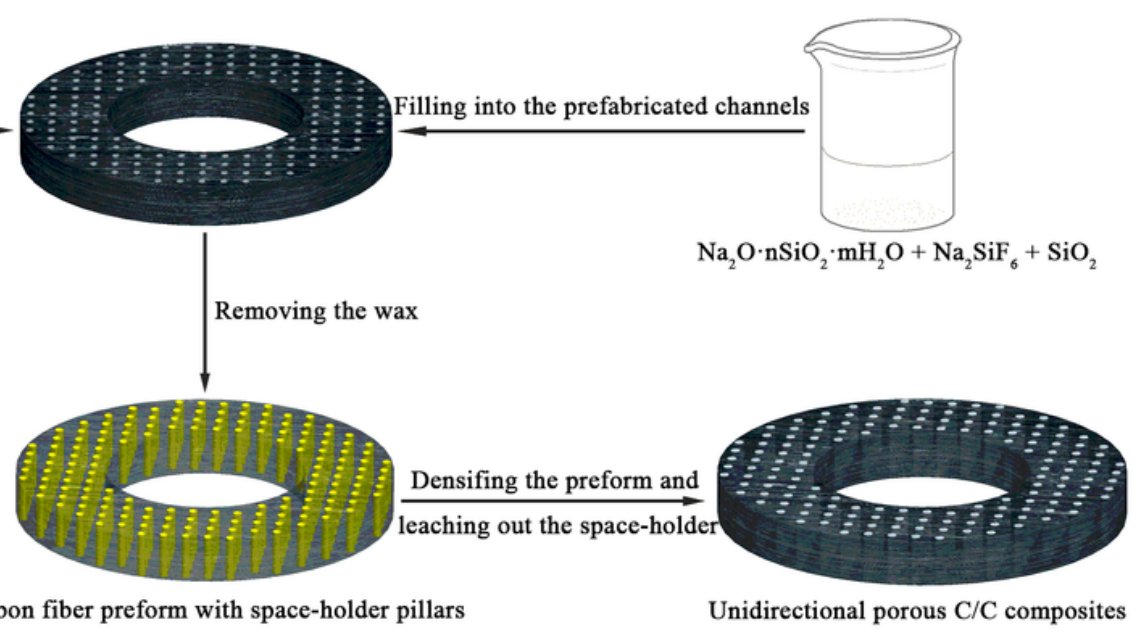

\section{Figure 1}

Flow diagram of preparation of unidirectional porous $\mathrm{C} / \mathrm{C}$ composites. 
(a)

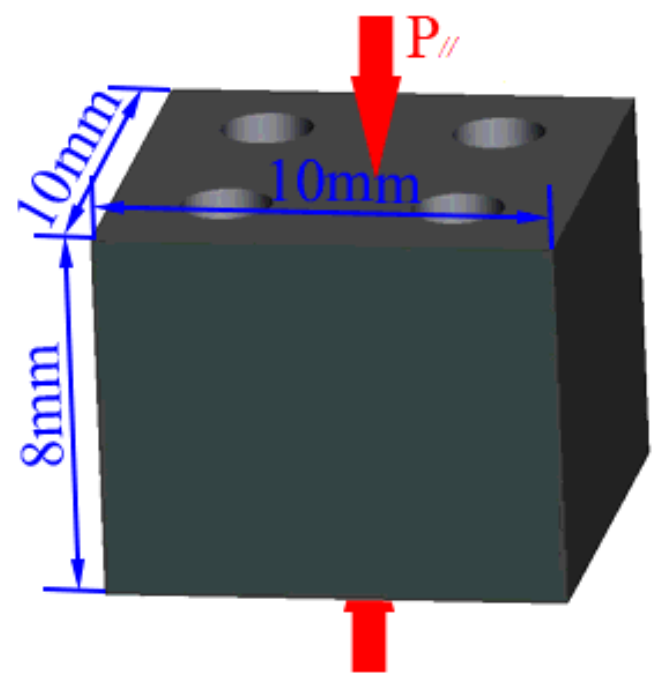

(c)
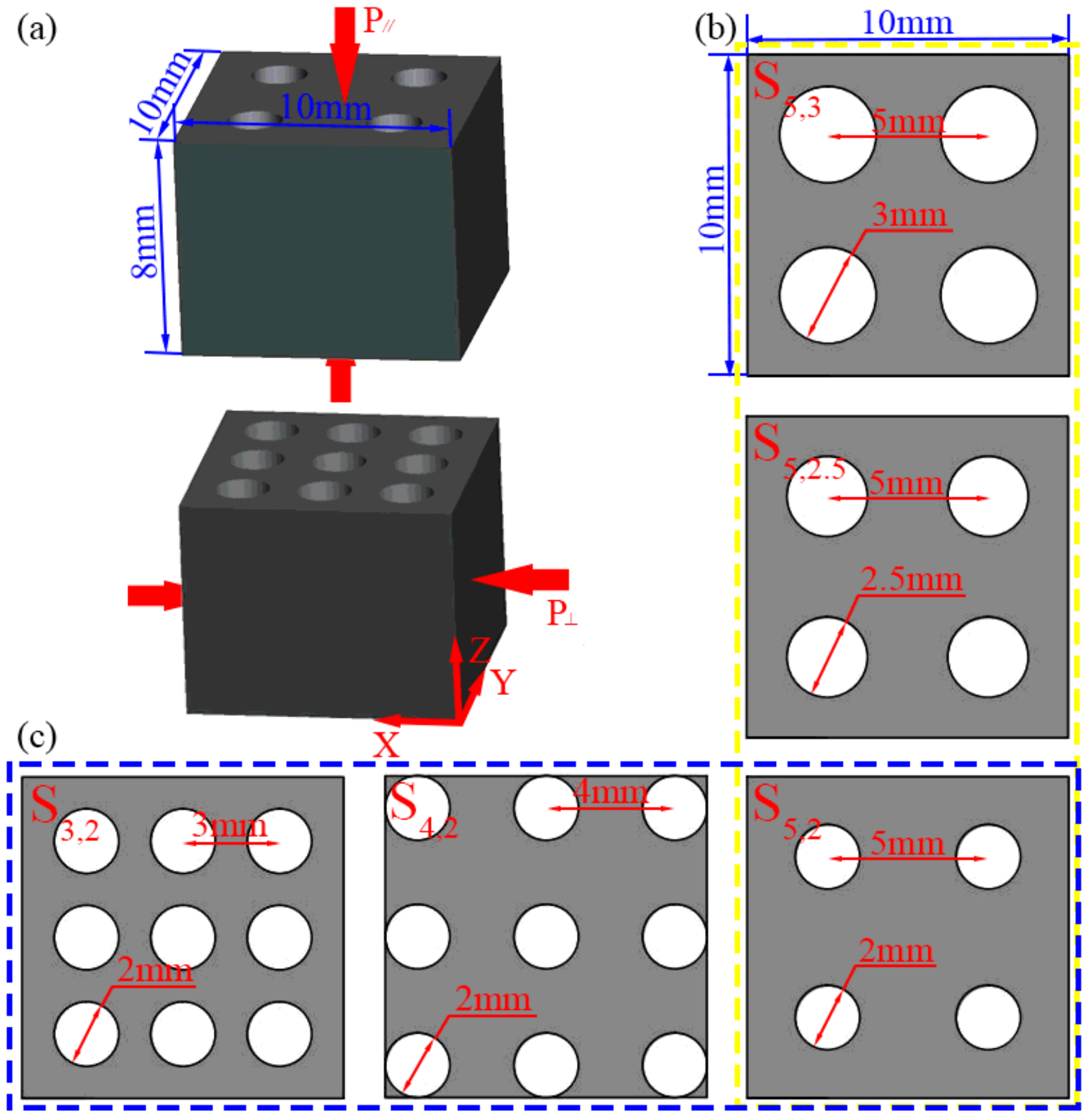

Figure 2

Schematic diagram and dimensions of porous C/C composite samples for compression (a), crosssectional views of the samples with different channel diameter (b) , and cross-sectional views of the samples with different channel-row spacing for P// (c). 

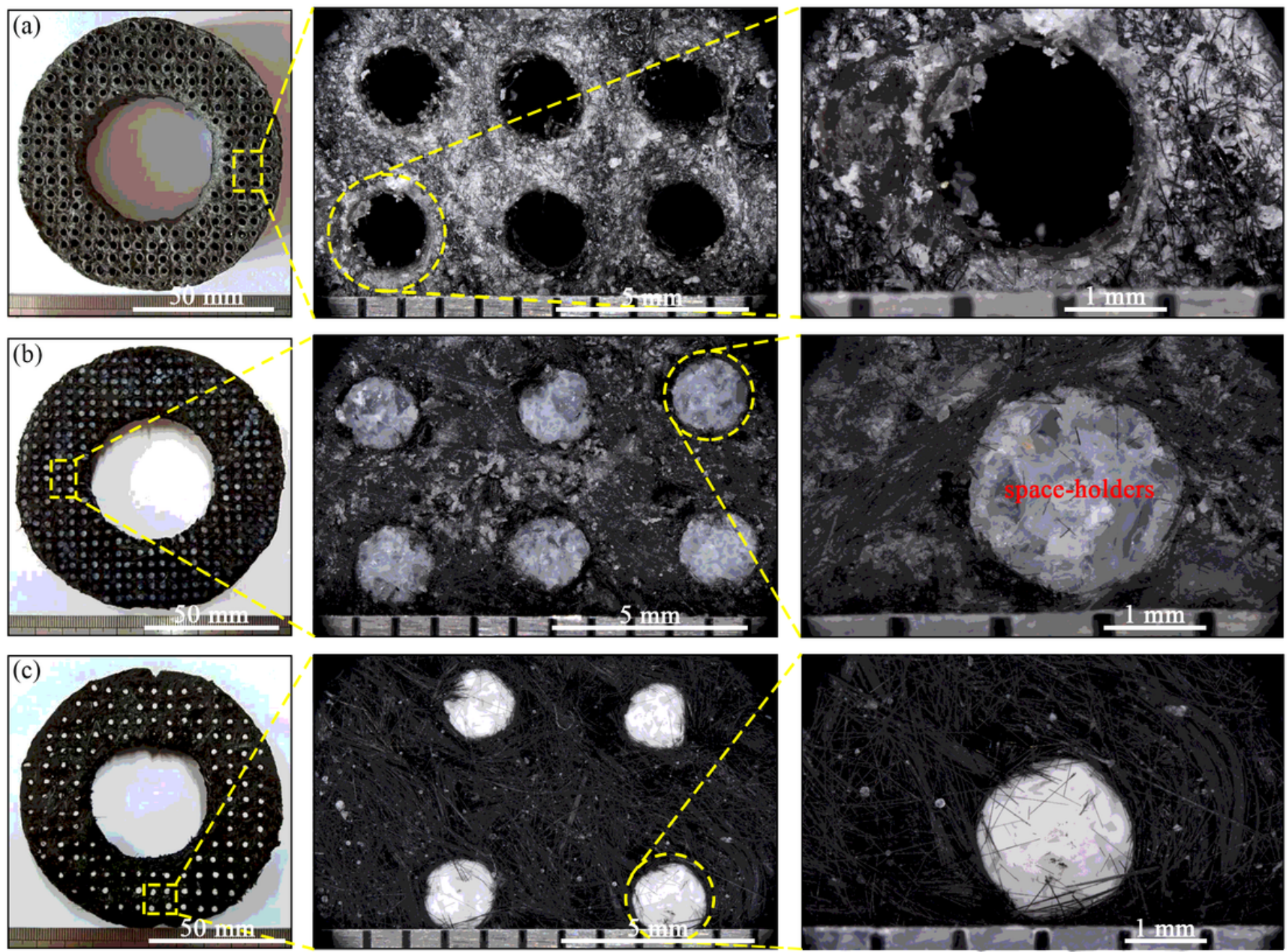

\section{Figure 3}

The morphologies of the carbon fiber preform at different stages of treatment before deposition: (a) Waximpregnated and needl-pounched; (b) space-holders filled; (c) Wax-removed. 

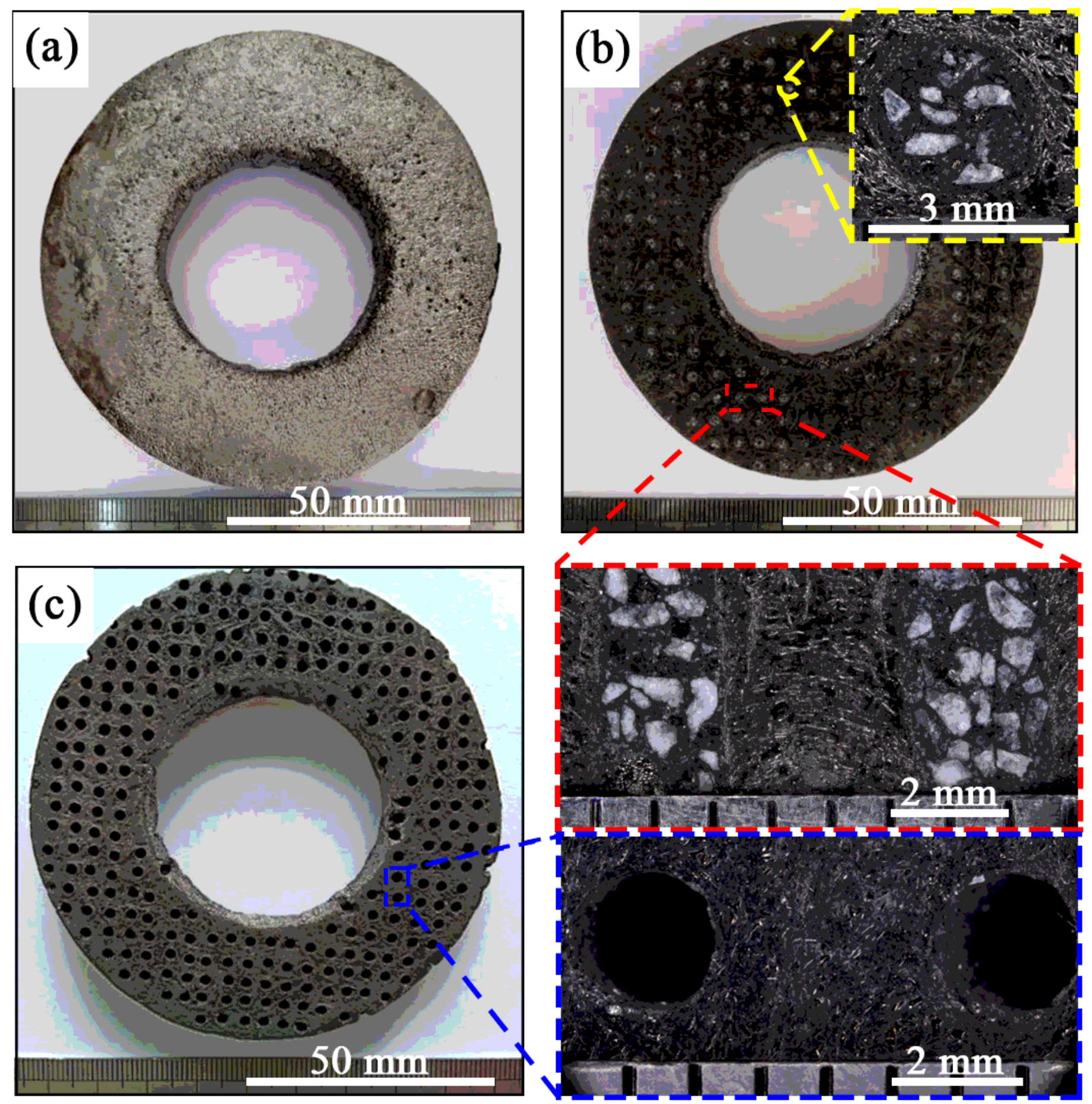

\section{Figure 4}

Different states of post-processing of the composites: (a) Macro-photograph of after the deposited state; (b) Macro-photograph of the composite after removing the thin PyC crust; (c) Macro-photograph of unidirectional porous $\mathrm{C} / \mathrm{C}$ composites after leaching out the space-holders. 

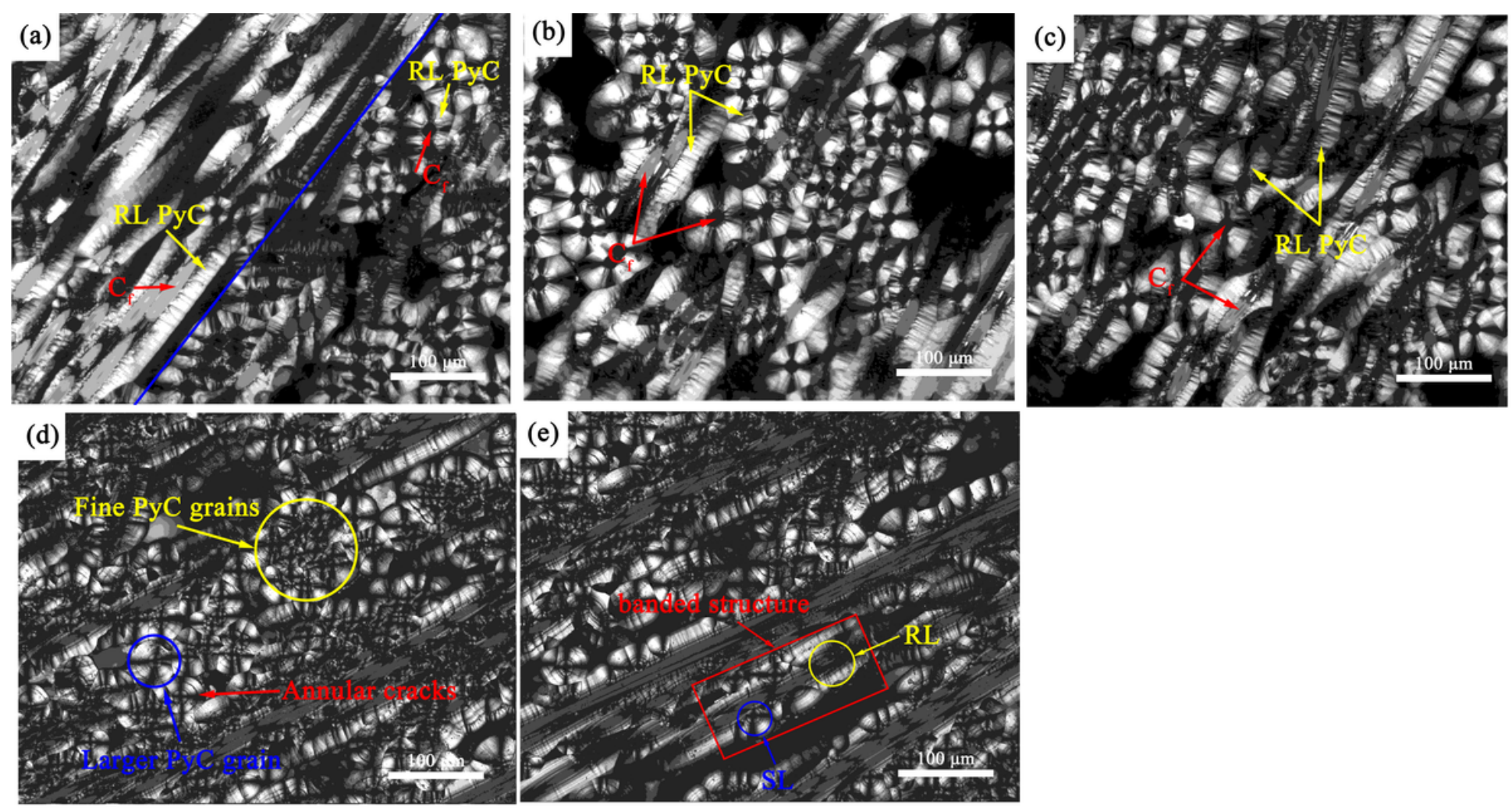

\section{Figure 5}

PLM microstructures of the porous C/C composites: (a) S5, 2; (b) S5, 2.5; (c) S5, 3; (d) S4, 2; (e) S3, 2.
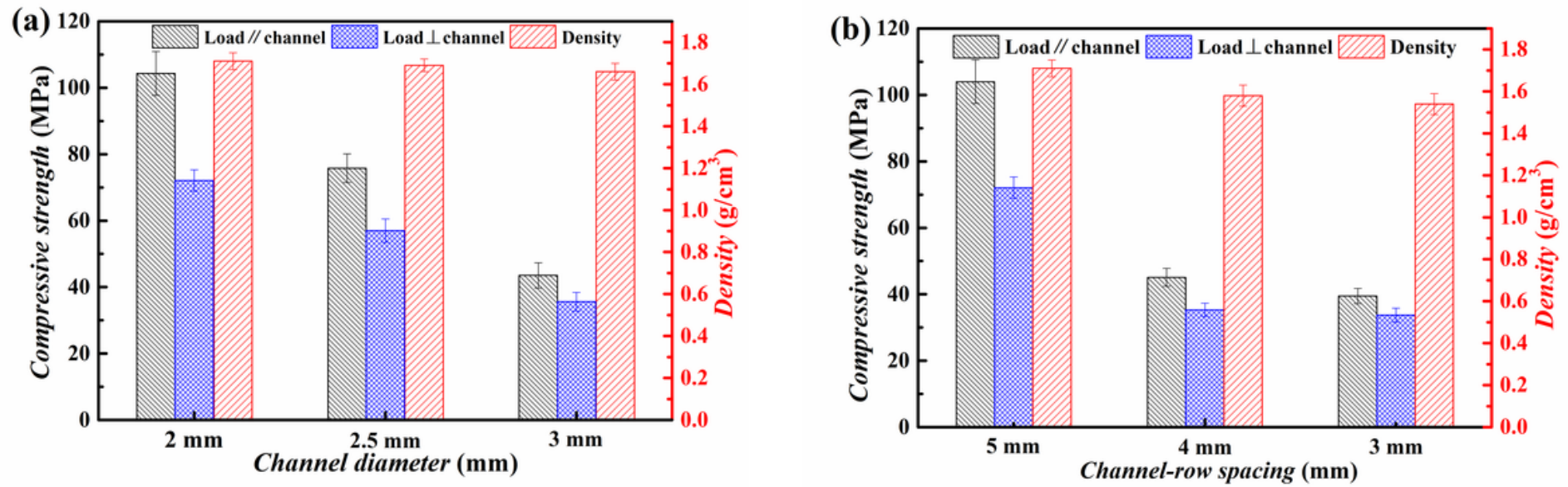

Figure 6

Properties of different unidirectional porous $\mathrm{C} / \mathrm{C}$ composite samples: (a) histogram of composites properties with the different channel-diameter; (b) histogram of composites properties with the different channel-row spacing. 

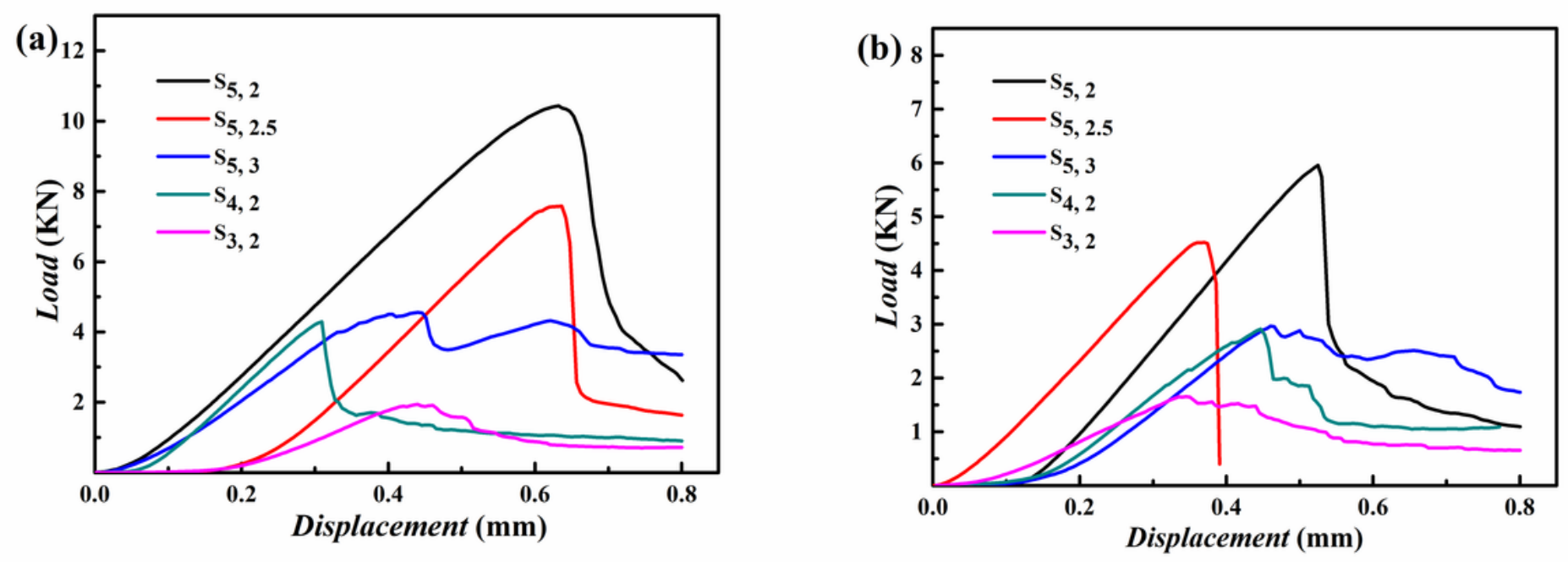

Figure 7

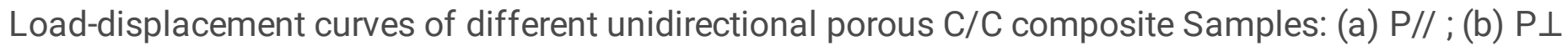
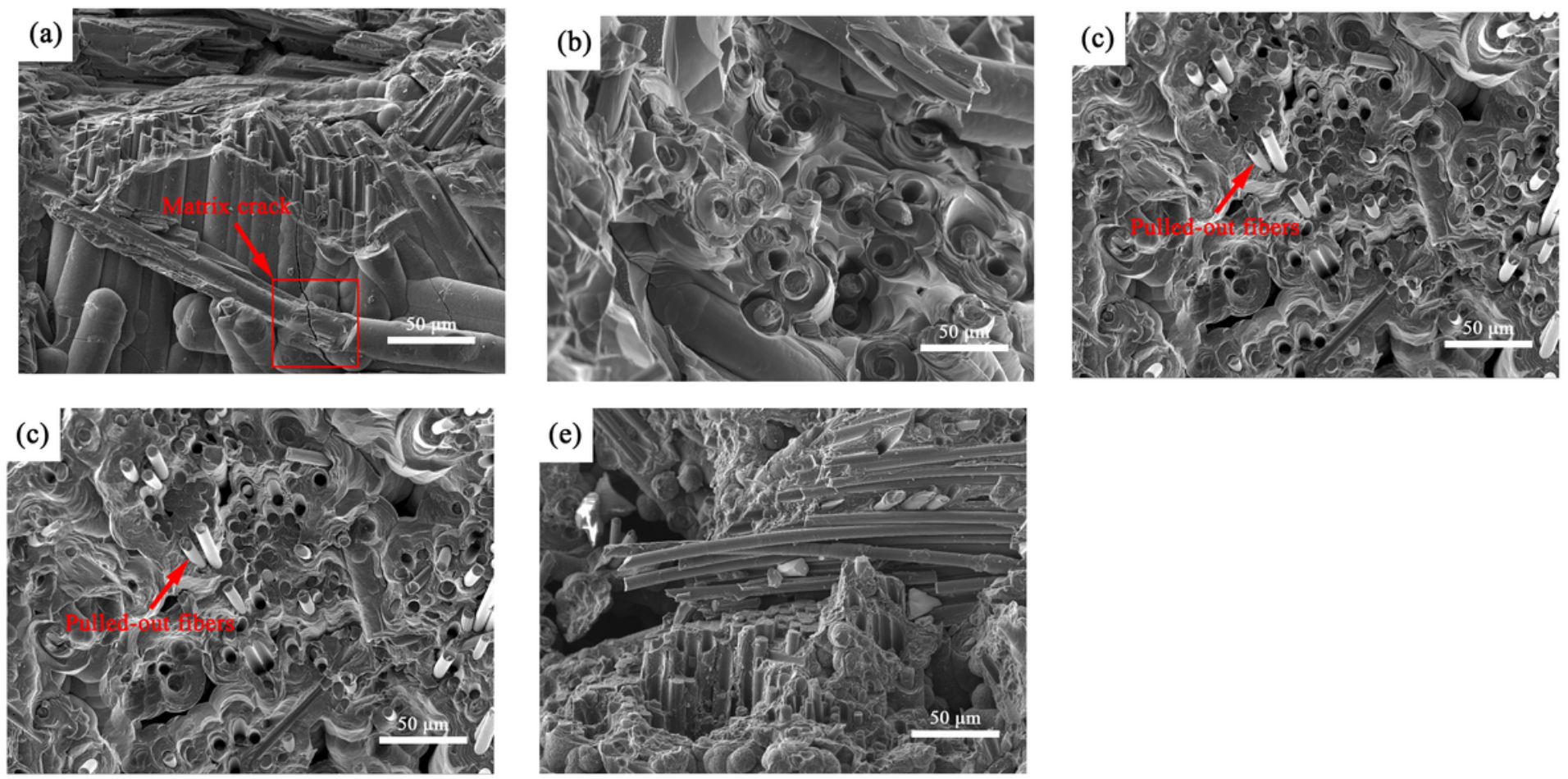

\section{Figure 8}

SEM fracture morphologies of different unidirectional porous C/C composite Samples: (a) S5, 2; (b)S5, $2.5 ;$ (c) S5, 3; (d) S4, 2; (e) S3, 2. 